\title{
Pengaruh Silinder Downstream terhadap Karakteristik Aliran Silinder Upstream Menggunakan Square Disturbance Body Tersusun Tandem
}

\author{
Rina $a^{1,2)^{*}}$, Sanny Ardhy ${ }^{3)}$ \\ ${ }^{1,3)}$ Program Studi Teknik Mesin Universitas Dharma Andalas, Jl. Sawahan No. 103A, Padang, Indonesia \\ 2) Jurusan Teknik Mesin, Politeknik Negeri Padang, Kampus Limau Manis, Padang, Indonesia \\ naskah masuk 29/08/2018; diterima 15/09/2018; terbit 29/10/2018 \\ doi: 10.24843/JEM.2018.v11.i02.p05
}

\begin{abstract}
Abstrak
Fluida yang mengalir di sekitar bluff body silinder sirkular, akan menimbulkan gaya-gaya aerodinamika salah satunya gaya drag. Drag sangat tidak diinginkan untuk keselamatan struktur body. Reduksi gaya drag dilakukan dengan mengontrol medan aliran seperti meningkatkan kekasaran permukaan, mengiris silinder dengan sudut iris tertentu, dan menempatkan pengganggu di sisi upstream silinder. Penelitian ini bertujuan untuk melihat pengaruh silinder downstream terhadap karakteristik aliran silinder upstream menggunakan square disturbance body yang disusun tandem pada saluran sempit. Geometri yang digunakan adalah dua silinder sirkular yang disusun tandem berdiameter (D) $25 \mathrm{~mm}$ dengan variasi jarak antar silinder (L/D) 1,5; 2; 2,5; 3; 3,$5 ;$ 4. Square Cylinder sebagai body pengganggu ditempatkan pada sisi upstream silinder utama berdiamensi 4 mm. Posisi sudut pengganggu (a) $30^{\circ}$, dan jarak gap $(\mathrm{d}=0.4 \mathrm{~mm})$. Reynolds number berdasarkan diameter silinder, yaitu ReD $2,32 \times 10^{4}$. Penelitian iini dilakukan secara numerik 2D Unsteady-RANS menggunakan CFD software FLUENT 6.3.26 dengan model viscous Turbulence Model Shear-Stress-Transport (SST) $k-\omega$. Parameter yang diamati adalah koefisien pressure (Cp), Koefisien drag pressure (Cdp) dan visualisasi aliran berupa velocity pathline. Hasilnya menunjukkan bahwa Penambahan silinder downstream memberikan kontribusi dalam pengurangan gaya drag pada silinder upstream menggunakan square disturbance body. Pengaruh wake silinder upstream terhadap silinder downstream berkurang dengan meningkatnya rasio L/D. Interaksi wake silinder upstream terhadap silinder downstream terjadi pada konfigurasi L/D 1,5 - 3. Pengurangan gaya drag optimum terjadi pada konfigurasi L/D 3.
\end{abstract}

Kata kunci: Silinder sirkular, square disturbance body, tandem, koefisien pressure, koefisien drag pressure, unsteady

\section{Abstract}

The fluid flows around the circular cylinder bluff body will produce aerodynamic forces, one of which is the drag force. Drag is very undesirable for the safety of the body structure. Reduction of drag force is carried out by controlling the flow field such as increasing the surface roughness, slicing the cylinder with a certain iris angle, and placing the disturbance on the upstream side of the cylinder. This purpose of the study is to see the effect of downstream cylinders on the flow characteristics of upstream cylinders using a square disturbance body arranged tandem in a narrow channel. The geometry used is two circular cylinders arranged in tandem diameter (D) $25 \mathrm{~mm}$ with a variation of distance between cylinders (L / D) 1.5; 2; 2.5; 3; 3.5; 4. Square Cylinder as a disturbing body is placed on the side of the main cylinder upstream with a diameter of $4 \mathrm{~mm}$. The position of the disturbing angle $(\alpha)$ is $30^{\circ}$, and the gap distance $(d=0.4 \mathrm{~mm})$. Reynolds number is based on cylinder diameter, ie ReD $2.32 \times 104$. This research was carried out numerical 2D Unsteady-RANS using a FLUENT 6.3.26 CFD software with viscous Turbulence model Shear-Stress-Transport (SST) k- $\omega$ model. Parameters observed were pressure coefficient (Cp), drag pressure coefficient (Cdp) and flow visualization in the form of velocity pathline. The results show that the addition of a downstream cylinder contributes to the reduction of the drag force on the upstream cylinder using a square disturbance body. The wake influence of upstream cylinder to downstream cylinder decreasing with increasing the ratio of $L / D$. The interaction of wake cylinder upstream to downstream cylinder occurs at L/D 1.5 - 3. The optimum for the drag force reduction occurs at L/D 3.

Keywords: Circular cylinder, square disturbance body, tandem arrangement, Pressure coefficient, coefficient drag pressure, unsteady

\section{Pendahuluan}

Beberapa aplikasi teknik menggunakan bentuk dasar bluff body silinder sirkular, seperti sistem perpipaan, struktur penyangga anjungan lepas pantai dan dermaga jembatan. Ketika silinder dialiri fluida, akan menimbulkan gaya drag yang begitu besar dan ini sangat merugikan. Telah banyak penelitian dilakukan dalam pengurangan gaya drag ini diantaranya dengan meningkatkan kekasaran permukaan, mengiris silinder dengan sudut iris tertentu, menambahkan pengganggu pada sisi upstream silinder atau menambahkan silinder downstream di belakangnya yang disusun secara tandem.
Lee,dkk [1] melakukan penelitian dalam pengurangan gaya drag menggunakan silinder sirkular tunggal dengan sebuah control rod yang ditempatkan di sisi upstream. la menvariasikan jarak longitudinal (L/D) antara geometri body dengan silinder utama, dan rasio dimensi kedua body (d/D). Hasil penelitiannya menunjukkan bahwa rasio $d / D$ pada $L / D$ yang sama dalam mereduksi gaya drag terjadi hingga $\mathrm{d} / \mathrm{D}=0,233$. Jika rasio $\mathrm{d} / \mathrm{D}$ lebih besar dari angka tersebut maka efektifitas dalam mereduksi gaya drag menjadi berkurang. Putra [2] dan Rina,dkk [3] menggunakan dua buah square disturbance body yang ditempatkan di sisi upstream silinder sirkular pada sudut tertentu. Hasil penelitian tersebut menunjukkan bahwa 
penempatan pengganggu di sisi upstream silinder sirkular memberikan kontribusi dalam pengurangan gaya drag. Nilai optimum dalam pengurangan gaya drag terdapat pada sudut pengganggu $a=30^{\circ}$. Alam,dkk [4], melakukan penelitian dengan memvariasikan jarak silinder upstream dan silinder downstream. Hasil penelitiannya menunjukkan bahwa terjadi bistable flow pada konfigurasi L/D 3, dan pencapaian pengurangan gaya drag terjadi pada sudut kontur $\alpha=30^{\circ}$ sebesar $67 \%$. Daloglu [5] menggunakan dua buah geometri body sirkular silinder dan square silinder. Di sisi upstream, divariasikan dua buah geometri, yaitu silinder sirkular dan square silinder. Sementara di sisi downstream tetap menggunakan silinder sirkular. Variasi jarak antar silinder $1<\mathrm{S} / \mathrm{d}<10$. Hasilnya menunjukkan bahwa variasi jarak antar silinder memberikan pengaruh terhadap reduksi gaya drag dengan rasio 1-1,5. Informasi lain bahwa square silinder mempunyai pressure drop lebih besar dari pada silinder sirkular. Kemudian Daman, dkk [6] melakukan penelitian menggunakan dua buah silinder sirkular yang disusun tandem dengan variasi L/D 1,5 4. Silinder upstream diberikan dua buah body pengganggu sirkular dengan sudut $60^{\circ}$. Hasil penelitiannya menunjukkan bahwa reduksi gaya drag hanya terjadi pada silinder downstream sedangkan pada silinder upstream kenaikan nilai koefisien drag maksimum terjadi sekitar $22 \%$ dari silinder tunggal. Dan konfigurasi optimum dalam pengurangan gaya drag terjadi pada L/D 1,5.

Dari beberapa penelitian tersebut, pembahasan tentang pengaruh silinder downstream terhadap karakteristik aliran silinder upstream menggunakan pengganggu square silinder pada sudut $30^{\circ}$ yang tersusun tandem belum dibahas, sehingga perlu dibahas lebih lanjut dengan menampilkan kontur visualisasi aliran pada simulasi numerik menggunakan CFD software FLUENT 6.3.26.

\section{Metode Penelitian}

Penelitian ini dilakukan melalui simulasi numerik menggunakan software Fluent CFD 2D UnsteadyRANS. Dua buah geometri body disimulasikan berbentuk silinder sirkular dengan diameter upstream dan downstream (D) $25 \mathrm{~mm}$, dimensi pengganggu square cylinder (d) $4 \mathrm{~mm}$, gap dari permukaan silinder upstream $(\delta)$ 0,4 $\mathrm{mm}$ pada sudut pengganggu $(\alpha) 30^{\circ}$. Variasi jarak silinder upstream dan downstream (L/D) 1,$5 ; 2 ; 2,5 ; 3 ; 3,5 ; 4$. Reynolds Number berdasarkan diameter silinder, yaitu $\operatorname{ReD} 2,32 \times 10^{4}$ dengan model viscous Turbuence Model Shear-Stress-Transport (SST) k- $\omega$. Domain simulasi numerik dapat dilihat pada gambar 1, dan meshing ditunjukkan pada gambar 2. Kondisi batas sisi inlet adalah velocity inlet dan sisi outlet adalah pressure outlet.

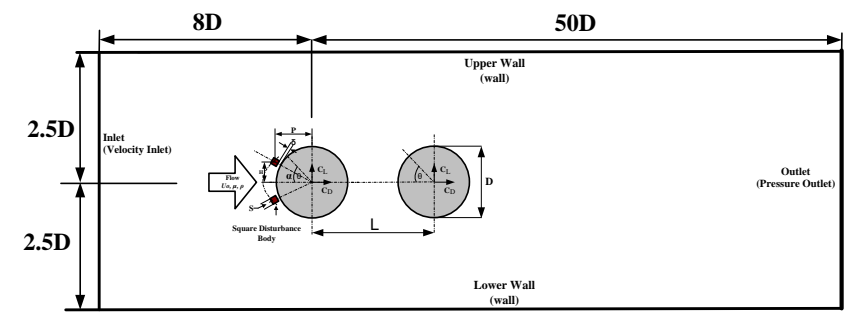

Gambar 1. Domain simulasi numerik

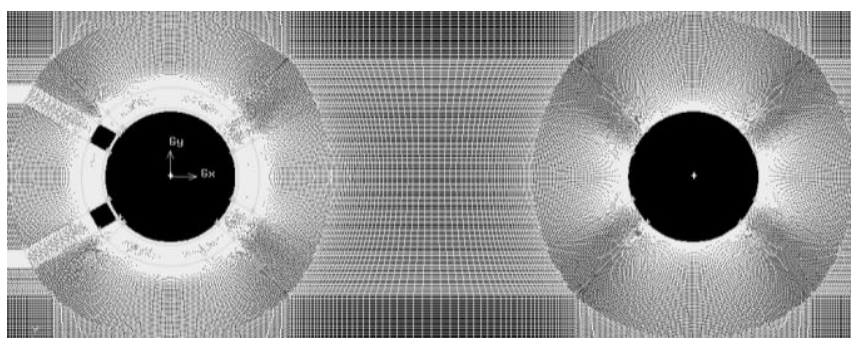

Gambar 2. Meshing qualidrateral map

\section{Hasil dan Pembahasan}

\subsection{Distribusi Tekanan Silinder Upstream}

Plot grafik distribusi tekanan silinder upstream dapat dilihat pada gambar 3. Dari plot tersebut terlihat bahwa dari semua konfigurasi termasuk silinder dengan pengganggu tanpa silinder downstream di belakangnya, umumnya menunjukkan trend grafik yang sama. Setelah titik stagnasi, aliran mulai mengalami akselerasi pada sudut $22^{\circ}$. Hal ini terjadi karena adanya gap (ס) dari permukaan silinder upstream (blockage effect). Namun terjadinya deselerasi dan separasi pada masing-masing konfigurasi mengalami perbedaan. Trend grafik (deselerasi dan separasi) hampir sama terjadi pada variasi $L / D$ 2,5; 3 ; 3,5; dan 4 , dimana titik separasi terjadi sekitar sudut $90^{\circ}$. Sedangkan pada L/D 1,5 dan 2 menunjukkan trend grafik yang bergelombang. Hal ini menandakan bahwa terbentuknya dua buah peak sepanjang permukaan silinder upstream $\left(0^{\circ}-180^{\circ}\right)$, yaitu pada sudut $50^{\circ}$ \& $120^{\circ}$ untuk L/D 1,5 dan $70^{\circ}$ \& $160^{\circ}$ untuk L/D 2. Adanya peak menandakan terbentuknya separation bubble dan terjadinya reattachment yang menyebabkan separasi tertunda lebih ke belakang, seperti yang dijelaskan pada penelitian sebelumnya oleh Rina [3]. Kecepatan maksimum diantara semua variasi L/D terjadi pada konfigurasi L/D 1,5. Untuk konfigurasi tanpa silinder downstream, separasi sudah terjadi pada sudut $85^{\circ}$.

\subsection{Koefisien Drag Pressure Silinder Upstream}

Gambar 4 menunjukkan perbandingan grafik Koefisien drag pressure silinder menggunakan square disturbance body dengan silinder downstream dan tanpa silinder downstream. Dari gambar dapat dilihat bahwa penambahan silinder downstream memberikan kontribusi yang lebih besar dalam pengurangan gaya drag. Hal ini dapat dilihat dari nilai Cdp yang dihasilkan untuk keseluruhan variasi $L / D$ berada dibawah nilai Cdp tanpa silinder downstream ( $\mathrm{Cdp}=0,57)$. Pengurangan gaya drag optimum terjadi pada konfigurasi L/D 3 dengan nilai Cdp 0,05. 


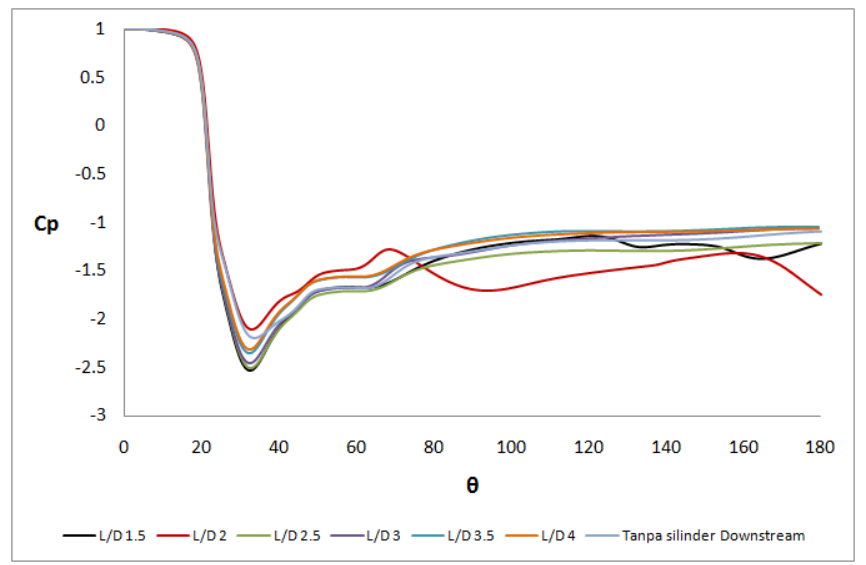

Gambar 3. Distribusi tekanan silinder upstream

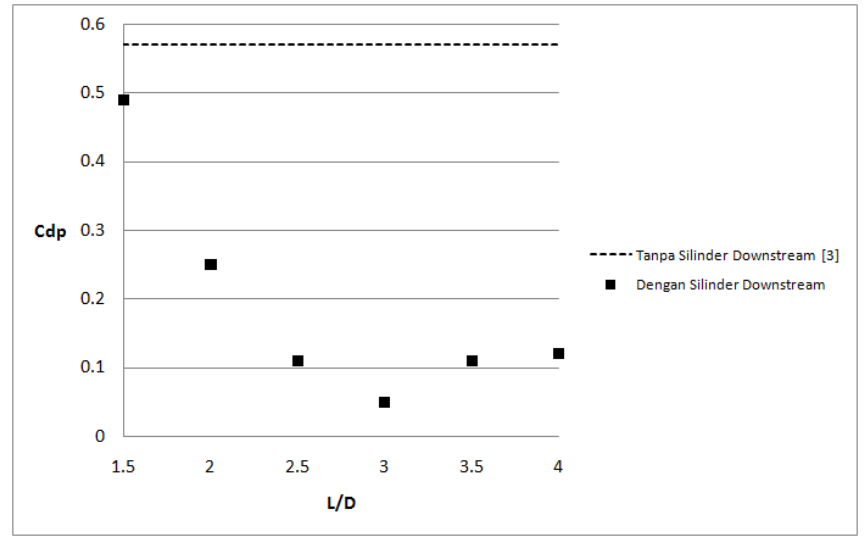

Gambar 4. Koefisien Drag Pressure silinder upstream

\subsection{Visualisasi Aliran (Velocity Pathline)}

Gambar 5 merupakan visualisasi aliran berupa velocity pathline. Titik stagnasi ditunjukkan oleh simbol SP (Stagnation Point), Titik Attachment ditunjukkan oleh simbol AP (Attachment Point), Separation bubble ditunjukkan oleh simbol SB dan Reattachment point ditunjukkan oleh simbol RP.

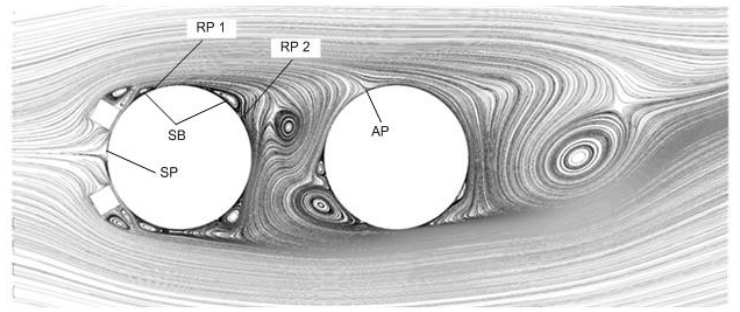

(a)

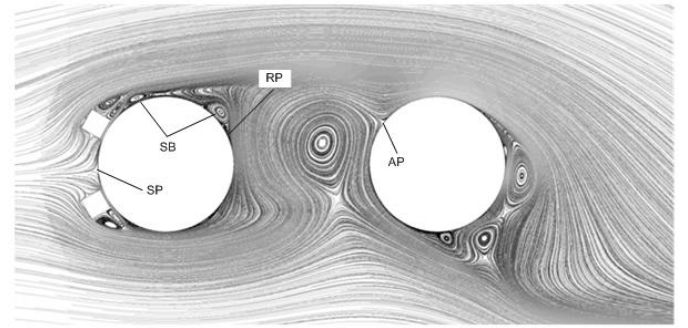

(b)

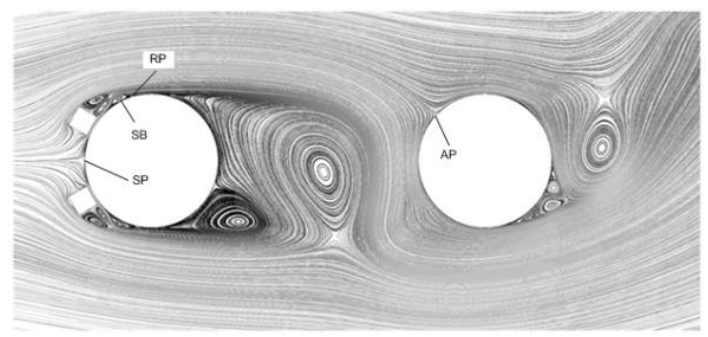

(c)

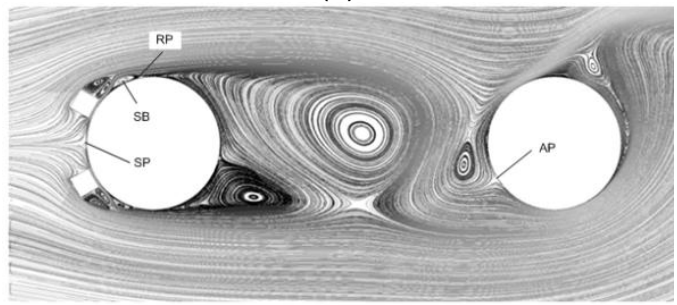

(d)

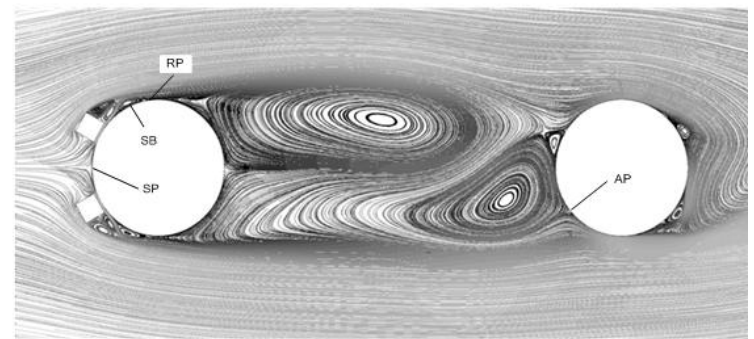

(e)

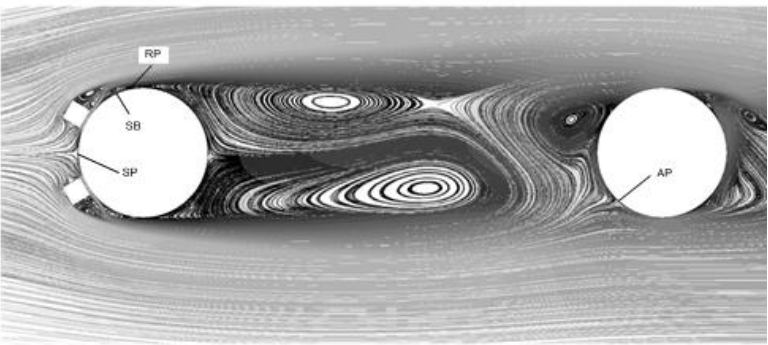

(f)

Gambar 5. Velocity Pathline pada L/D: (a) 1,5; (b) 2; (c) 2,5 ; (d) 3 ; (e) 3,$5 ;$ (f) 4

Dari gambar 5 dapat dilihat bahwa pada L/D 1,5 dan 2 terbentuk dua buah separation bubble di sepanjang permukaan silinder upstream $\left(0^{\circ}-180^{\circ}\right)$. Separation bubble terjadi akibat adanya adverse pressure yang dipengaruhi oleh kelengkungan kontur permukaan silinder. Namun karena adanya shear layer yang terlepas dari body pengganggu yang berinteraksi dengan boundary layer pada permukaan silinder sirkular, menambah momentum untuk aliran kembali attach pada permukaan silinder sirkular upstream yang ditandai dengan simbol RP1 (gambar 5 a). Namun karena wake silinder upstream melingkupi silinder downstream lalu terdesak ke bagian belakang silinder upstream sehingga terbentuk lagi separation bubble kira-kira pada sudut kontur 120 untuk L/D 1,5 dan $160^{\circ}$ untuk L/D 2 (gambar $5 a$ dan 5b). Aliran mengalami attachment pada bagian atas silinder downstream.

Sedangkan pada L/D 2,5 - 4, menunjukkan bentuk visualisasi aliran seperti tanpa penambahan silinder downstream pada penelitian sebelumnya Rina [3]. Jarak antar silinder upstream dan downstream 
yang sudah mulai cukup jauh, mengakibatkan interaksi wake silinder upstream terhadap silinder downstream juga mulai berkurang. Hal ini ditunjukkan pada konfigurasi L/D 3,5 dan 4 dengan nilai Cdp yang mulai mengalami peningkatan (gambar 4). Untuk aliran pada silinder downstream bentuknya hampir sama dengan silinder tunggal, akan tetapi titik stagnasi masih bergeser dari sudut kontur $0^{\circ}$.

\section{Simpulan}

Penelitian mengenai pengaruh penambahan silinder downstream terhadap silinder upstream menggunakan pengganggu square disturbance body yang disusun tandem telah dilakukan secara numerik. Dari pembahasan tersebut dapat disimpulkan bahwa:

1. Penambahan silinder downstream memberikan kontribusi dalam pengurangan gaya drag pada silinder upstream menggunakan square disturbance body.

2. Interaksi wake silinder upstream terhadap silinder downstream terjadi pada konfigurasi L/D 1,5 - 3 .

3. Pengurangan gaya drag optimum terjadi pada konfigurasi L/D 3.

\section{Ucapan Terima Kasih}

Penulis mengucapkan terima kasih kepada Ristekdikti yang telah memberikan dukungan financial terhadap penelitian ini. Kemudian ucapan terima kasih kepada Politeknik Negeri Padang yang telah memberikan izin menggunakan laboratorium Komputer selama melakukan penelitian ini.

\section{Daftar Pustaka}

[1] Lee, Sang-Soon., Lee, Sang-lk., Park, CheolWoo, Reducing the drag on a circular cylinder by upstream installation of a small control rod, Fluid dynamics research Vol. 34, 233-250, 2004

[2] Putra, R.P, Reduksi gaya hambat pada silinder sirkular dan reduksi pressure drop pada saluran sempit berpenampang bujur sangkar dengan menggunakan batang pengganggu berbentuk square cylinder. Tesis, Institut Teknologi Sepuluh Nopember, Surabaya, 2013.

[3] Rina., Widodo, W. A, Simulasi Numerik Aliran di Sekitar Circular Cylinder dengan Dua Square Cylinder sebagai Disturbance Body pada Saluran Sempit. Thermofluid VI. 29 April 2014, Yogyakarta, Indonesia. Hal. 111-116, 2014

[4] Alam, M.D., Sakamoto. H., Moriya, M, Reduction of fluid forces acting on a single circular cylinder and two circular cylinders by using tripping rods. Jurnal of fluids and structures Vol. 18, 347-366, 2003.

[5] Daloglu, A, Pressure drop in a channel with cylinders in tandem arrangement. International Communication in Heat and Mass Transfer 35, 76-83, 2008
[6] Daman, A. A. A., Widodo, W. A, Pengaruh Penambahan Inlet Disturbance Body Terhadap Karakteristik Aliran Melintasi Silinder Sirkular Tersusun Tandem. Thermofluid VI. 29 April 2014, Yogyakarta, Indonesia. Hal. 79-84, 2014.

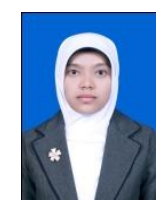

Rina menyelesaikan pendidikan S1 Teknik Mesin di Universitas Negeri Padang tahun 2012. Pendidikan magister Teknik Mesin diselesaikan di Institut Teknologi Sepuluh Nopember Surabaya pada tahun 2014 dengan area riset tentang Computational Fluid Dynamics.

Saat ini bekerja sebagai dosen di Program Studi Teknik Mesin Universitas Dharma Andalas dan Politeknik Negeri Padang. Bidang penelitian utama yang digeluti adalah Computational Fluid Dynamics (CFD). 